\title{
Considerations on sand control in natural gas wells
}

\author{
Ion Foidaş ${ }^{1, *}$, and Dan-Paul Ștefănescu ${ }^{2}$ \\ ${ }^{1}$ Lucian Blaga University of Sibiu, Faculty of Engineering, 4 E. Cioran st., 550025 Sibiu, Romania \\ ${ }^{2}$ Lucian Blaga University of Sibiu, Faculty of Engineering, 4 E. Cioran st., 550025 Sibiu, Romania
}

\begin{abstract}
Mechanism of sand production in gas wells is complex and influenced by every operation performed into the well, starting from the opening of the production interval by drilling, and continuing with completion and putting into production as well as with the exploitation regime. Sand production along with fluids from gas reservoirs creates a series of potentially dangerous and costly problems. For selecting the most appropriate methods of sand-control all the data and information related to properties of reservoir rock, the history of sand production, the potential well flow rates as well as HSE and costs need to be evaluated. The conclusion of the authors is that the best results in sand control is achieved when the methods are applied before the production of sand may become an issue.
\end{abstract}

\section{Introduction}

One of the problems that natural gas producers are facing during wells operation is the appearance of sand from the production unit into the formation fluids. This happens when the well produces from a weakly consolidated formation, where detachment of solid particles (called sand) from the rocks is possible, those particles being driven by layer fluids and getting into the boreholes and even at surface where they can lead to erosion of the production equipment.

The sand that entered into the well can deposit on the bottom and, in time, it can cover the perforations, forming sand plugs in the tubing and in the annulus between the tubing and production casing, as well. Accumulation of sand into the well decreases and even stops the influx of formation fluid. In this case, the production should be stopped and the wellbore cleaned, not always a successfully operation, but incurring always significant costs.

On the other hand, after sand floods from formation into the well, inside there will be disorders, forming caverns behind production casing, which could damage the casing and lead to the collapse of the impermeable rock above the production layer. Consequently, water layers can be opened that deteriorate the productive formation and as a result, production difficulties may occur.

The technologies used to stop problems caused by sand carrying over from the productive formation are diverse and continually enhanced. All these technologies except one (production restricting) imply consolidation of the formation from the area adjacent to the productive interval, to prevent sand movement because of the extracted fluids or of layer well differential pressure.

\footnotetext{
* Corresponding author: ion.foidas@ulbsibiu.ro
} 


\subsection{Sand control by restricting gas flow rate}

Restricting the gas flow rate is the simplest method that can be applied to prevent the occurrence of sand floods into the wells. In some cases, it can be a successful alternative, but in most cases, it is not a sustainable or economical method.

Thus, the natural gas wells that produce from poorly consolidated formations cannot be operated at nominal rates but at much lower rates not to produce sand floods from the formation. For each case, the maximum allowable flow rate a well produces can be determined, without having problems due to formation sand (Figure 1).

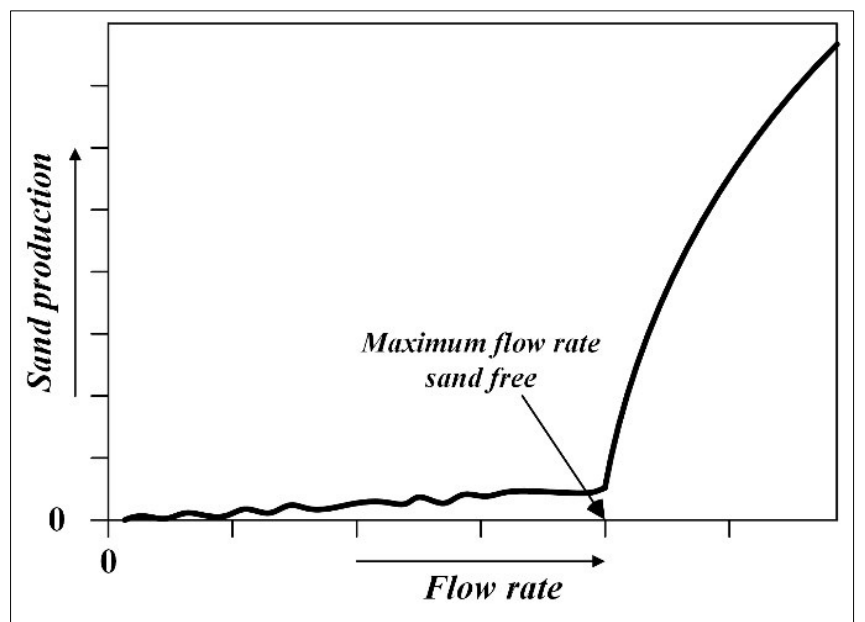

Fig. 1. Influence of the well flow rate on the sand production from a non-consolidated formation

As an indication, one can consider a maximum acceptable amount of sand produced by a well to be $8 \mathrm{mg} / \mathrm{m}^{3}$ for the wells producing gas with flow rate higher than $2,000 \mathrm{~m}^{3} /$ day and $16 \mathrm{mg} / \mathrm{m}^{3}$ in wells with flow rate lower than $2,000 \mathrm{~m}^{3} /$ day.

Maximum flow rate allowable for a well is determined using an equation based on the condition that the actual maximum gas velocity in the formation-well influx area should not reach the value where the rock grains (sand) are driven into the wellbore:

$$
Q_{m}=2 \pi r_{s} h v_{m}
$$

where $Q_{m}$ - the maximum flow rate under the conditions of the well-layer interface to which rock grains begin to enter into the wellbore;

- $r_{s}$ - the well radius;

- $h$ - thickness of the production layer;

$-v_{m}$ - maximum gas filtration velocity in the influx formation-well area at which the granules begin to penetrate the rock into the well bore.

Because gas flow rate is usually expressed under standard conditions, applying the state gas equation, relation (1) becomes:

$$
Q_{m_{s t}}=2 \pi r_{s} h v_{m} \frac{T_{s t}}{T_{z}} \frac{p_{d p}}{p_{s t}} \frac{1}{Z}
$$

where $Q_{m_{s t}}$ - is the maximum gas flow rate in standard conditions;

- $p_{d p}$ - perforations dynamic pressure;

- $Z$ - gas compressibility factor;

- $T_{z}$ - reservoir temperature. 
Equation (2) can be written as:

$$
Q_{m_{s t}}=\frac{W p_{a d}}{Z}
$$

where $W=2 \pi r_{S} h v_{m} \frac{T_{s t}}{T_{z}}$ - velocity factor, which contains the maximum filtration velocity; - $p_{a d}=\frac{p_{d p}}{p_{s t}}$ - dynamic pressure at the perforations, dimensionless expressed relative to standard pressure.

From equation (3) one can calculate the velocity factor W:

$$
W=\frac{Q_{m_{s t}}}{p_{a d}} Z
$$

The velocity factor must be maintained constant during the production of the well, not to cause sand inflow into the well.

According to the equation (3) if the velocity factor $W$ has a constant value throughout the entire life of the well, the admissible flow rate decreases proportionally to the dynamic bottom pressure.

In practice, for determining the velocity factor, a special equipment can be used which allows the real time monitoring of solid particles from the well, operating based on the principle of sensing the noise produced by the collision of sand to the inner wall of a pipe which conveys the produced gas. Thus, the solid particles in the gas stream which hit the inner wall of the pipe generate ultrasonic signals that circulate through the pipe wall and which can be sensed by an acoustic sensor, from where they will be picked up and processed to determine the exact amount of sand coming from the well.

The sensor's location is preferred to be at a bend where fluid flow changes its direction of movement so that the noise from the collision of sand with the inner wall to be maximum.

The data collected by the sensor are input in a dedicated software which filters them and processes them, providing information about the amount of sand coming from the well according to production data and well actual conditions.

Introducing the gas volume factor expression $\left(b_{g}\right)$ in equation (2) it becomes:

$$
Q_{m_{s t}} b_{g}=2 \pi r_{s} h v_{m}
$$

For wells producing from weak consolidated formations $Q_{m_{s t}} b_{g}$ should be kept constant during exploitation in order to prevent the appearance of sand into the well [1].

For safe well exploitation, the maximum allowable flow rate is considered excessive and therefore the well will be operated with a lower flow rate, 0.9 usually from the last flow rate at which the well did not carry off rock particles.

In most cases, however, restricting the flow of production is not sufficient to stop the sand movement; the degree of formation consolidation, type and amount of the cementing materials and the amount of water that is produced by the well are also significant factors in sand carrying off. These factors may cause sand floods into the well, although production flow rate has been severely restricted. As a conclusion, we can say that even if the restriction of flow rate has as effect, in a first stage, preventing the appearance of sand into the well, this success may be short-lived, depending on how other factors act on formation sand during well exploitation.

\subsection{Sand flood control by mechanical control methods}

The mechanical sand control methods consist of wells downhole completion/recompletion with mechanical devices capable to block the influx of sand into well. These devices are 
slotted liners, wire-wrapped screens, prepacked filters, sintered filters, expandable sand screen etc.

The devices most commonly used are the wire-wrapped screens, made of a piece of tubing or pipe, of various lengths, over which spacers are welded, on which a special wire with up to $2.5 \mathrm{~mm}$ diameter is wound. The tubing is provided with circular holes of $8-10 \mathrm{~mm}$ or with slits with relatively large widths for fluids access (Figure 2).

The wire is made of stainless steel with a trapezoidal or triangular cross-section, and is wrapped with the narrower side inwardly positioned in order to ensure the filter's selfcleaning action [2]. The wire is welded at every connection point with the spacers in order to maintain an equal distance between coils/ gauges.

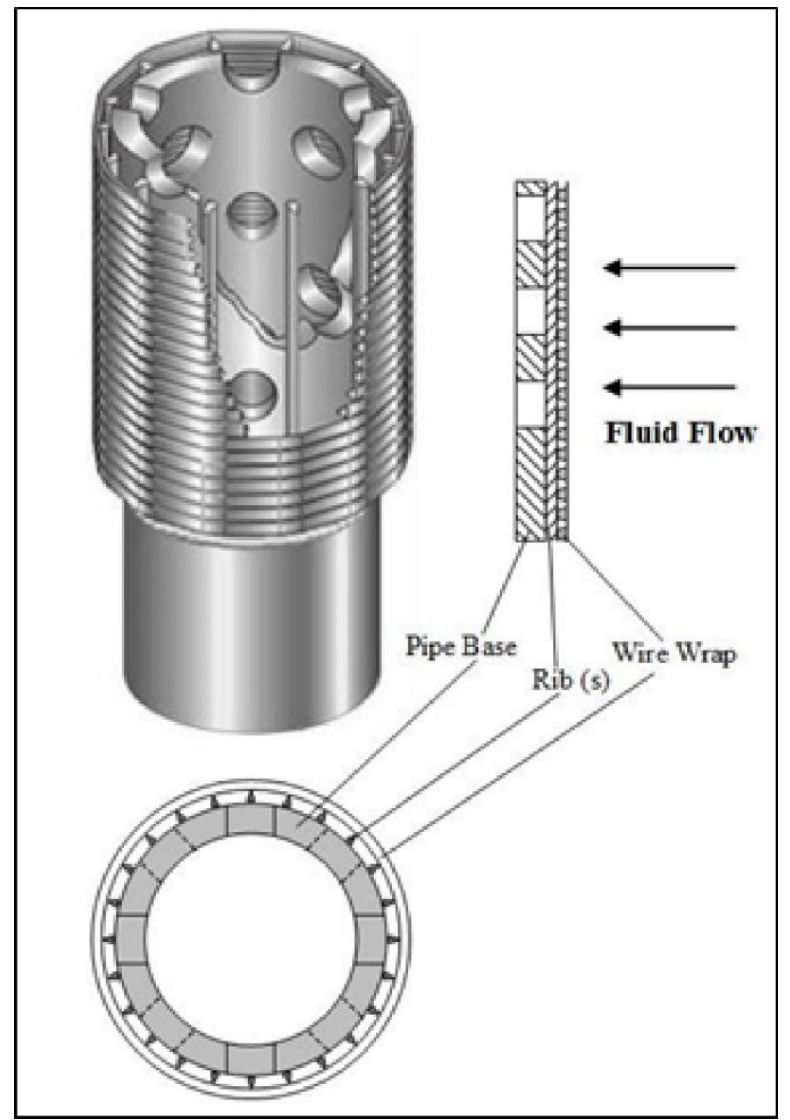

Fig. 2. Wire-Wrapped Screen.

The classical method of controlling sand floods consists of gravel packing the metal filter, which is fixed against perforation by using a packer.

The purpose of the wrapping is to provide an extended artificial filtering area in order to stop efficiently the sand carried - over by the fluid flow but also to create a flow resistance as small as possible (Figure 3). To achieve these two main purposes, a gravel for packing with larger dimensions should be used but also being capable to block the smallest particles from the formation. 


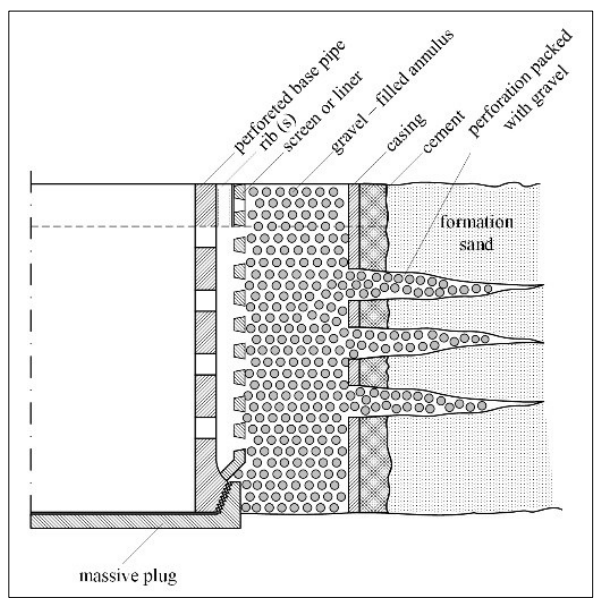

Fig. 3. Detail of internal gravel pack.

The filter wire is designed to retain gravel sand packing particles, which is why the distance between screen gauges must be less than the diameter of the smallest granules of gravel sand packing. Therefore the filters selection is done based on particle's size of the gravel sand packing, which is also chosen depending on sand layer's characteristics.

Sand layers characteristics are obtained after carrying out the particle size analysis of a sand sample derived from the productive formation, following these steps:

- weigh just a sample of sand and sieve, consecutively, through a set of sieves that have progressively smaller openings;

- determine the weight of sand passed through each sieve and is expressed as a percentage of the total sample weight;

- in a coordinate system plot the points, having as ordinate, the cumulative percentage of the amount of sand remained on each sieve and/or the percentage of the amount of sand passed through a sieve of a certain size (percentage), characterized by sieve's mesh diameter, indicated on the $\mathrm{x}$-axis to a logarithmic scale.

For example, below, are presented the results of particle size analysis of a sand layer sample derived from a well in Glavănești structure (Bacău County) [3].

Data on sieve's mesh size and data on sand quantity, which has passed through each sieve, are shown in Table 1, and their graphical representation is shown in Figure 4.

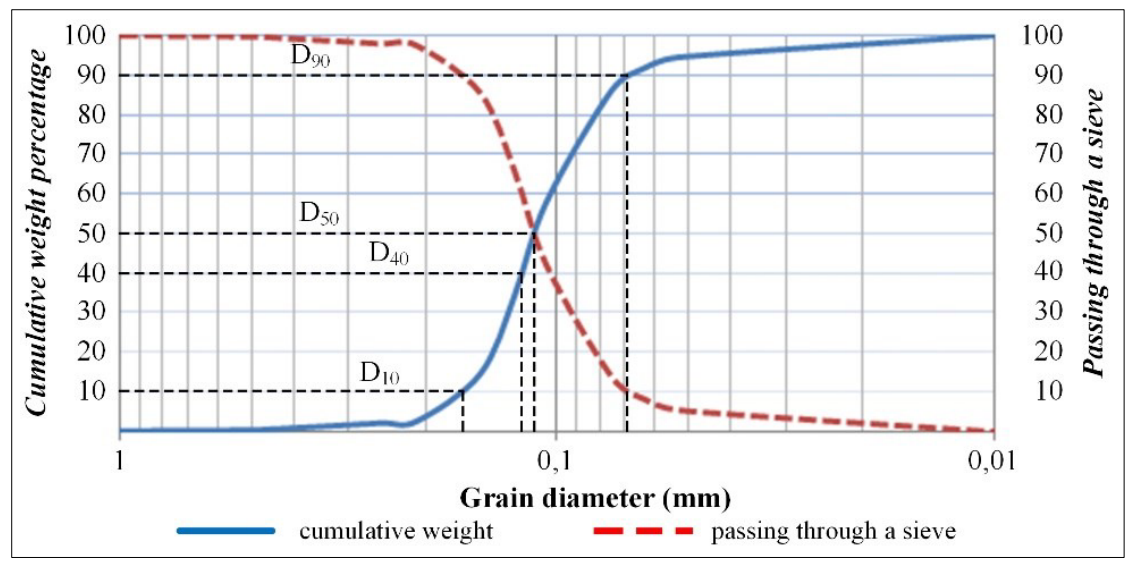

Fig. 4. The grading curve of sand from Glăvănești structure. 
Table 1. Particle size analysis results

\begin{tabular}{|c|c|c|c|c|}
\hline Size sieve & $\begin{array}{c}\text { Weight on } \\
\text { sieve }\end{array}$ & $\begin{array}{c}\text { Cumulative } \\
\text { weight }\end{array}$ & $\begin{array}{c}\text { Cumulative } \\
\text { weight }\end{array}$ & $\begin{array}{c}\text { Passing through } \\
\text { a sieve }\end{array}$ \\
\hline $\mathrm{mm}$ & grams & grams & $\%$ & $\%$ \\
\hline 1 & 0 & 0.00 & 0.00 & 100.00 \\
\hline 0.85 & 0.01 & 0.01 & 0.10 & 99.90 \\
\hline 0.5 & 0.02 & 0.03 & 0.30 & 99.70 \\
\hline 0.42 & 0.04 & 0.07 & 0.70 & 99.30 \\
\hline 0.3 & 0.09 & 0.16 & 1.60 & 98.40 \\
\hline 0.25 & 0.05 & 0.21 & 2.10 & 97.90 \\
\hline 0.21 & 0.04 & 0.25 & 2.50 & 97.50 \\
\hline 0.15 & 1.2 & 1.45 & 14.50 & 85.50 \\
\hline 0.125 & 2 & 3.45 & 34.50 & 65.50 \\
\hline 0.106 & 2.33 & 5.78 & 57.80 & 42.20 \\
\hline 0.075 & 2.84 & 8.62 & 86.20 & 13.80 \\
\hline 0.063 & 0.56 & 9.18 & 91.80 & 8.20 \\
\hline 0.053 & 0.27 & 9.45 & 94.50 & 5.50 \\
\hline 0.01 & 0.55 & 10.00 & 100.00 & 0.00 \\
\hline TOTAL & 10.00 & \multicolumn{3}{|l}{} \\
\hline
\end{tabular}

From the grading curve is shown that the sample's larger granules have a diameter below $1.0 \mathrm{~mm}$ because through the sieve with mesh of $1 \mathrm{~mm}, 100 \%$ of the sample passes, and the smallest granules have a diameter of about $0.01 \mathrm{~mm}$.

By the grading curve traced like this, the sand layer can be characterized. First of all, four points are located on the grading curve to give the following characteristic sizes (Fig. 4):

$>D_{10}=$ maximum size of the largest $10 \%$ of the sample;

$>D_{40}=$ maximum size of the largest $40 \%$ of the sample;

$>D_{50}=$ maximum size of the largest $50 \%$ of the sample;

$>D_{90}=$ maximum size of the largest $90 \%$ of the sample.

From these characteristic sizes, the following grading characteristics are defined:

$\checkmark$ Effective size, $D_{90}$

$\checkmark$ Median diameter, $D_{50}$

$\checkmark \quad$ Uniformity coefficient, $U c=D_{40} / D_{90}$

Depending on the uniformity coefficient, the formation sand may be classified as shown in table 2 .

Table 2. Classification of formation sand [4]

\begin{tabular}{|l|l|}
\hline$U_{c}<3$ & well sorted, highly uniform sand \\
\hline $3<U_{c}<5$ & uniform sand \\
\hline$U_{c}>10$ & moderate/poorly sorted sand \\
\hline $5<U_{c}<10$ & poorly sorted highly non-uniform sand \\
\hline
\end{tabular}

The gravel pack sand may be selected once the formation sand has been characterized.

There are a number of criteria used [4]:

\section{a. Saucier's Method}

$\mathrm{D}_{50}($ grain $)=4$ to 8 times $D_{50}$ (sand)

\section{b. Schwartz Uniformity Method}

$D_{10}$ (grain) $=6 \times D_{10}$ (sand) for $U_{c}<5$ uniform sand

$D_{40}$ (grain) $=6 \times D_{40}$ (sand) for $U_{c}>5$ poorly sorted highly non-uniform sand

$D_{70}$ (grain) $=6 \times D_{70}$ (sand) for $U_{c}>10$ moderately uniform sand

Usually Saucier method is used to determine the variation limits of sand sizes used to gravel packing, modified as follows: amplify by 5 , namely by 6 the size of $50 \%$ of the 
formation sand, afterwards chose the gravel sand with the median grain size ranging between the two limits, from the commercial offer.

Gravel pack sand is supplied in different sizes, the most used are: 40 - 60, 20 - 40, 12 -20; the first number represents the mesh, though which all grains fall downwards in the sieve, where all particles are gathered.

Table 3 shows the main properties of these gravel sand types:

Table 3. Properties of gravel pack sands [4]

\begin{tabular}{|c|c|c|c|c|c|}
\hline $\begin{array}{c}\text { Sand } \\
\text { size }\end{array}$ & $\begin{array}{c}\text { Range gravel } \\
\text { size }\end{array}$ & $\begin{array}{c}\text { Median gravel } \\
\text { diameter }\end{array}$ & $\begin{array}{c}\text { Average } \\
\text { permeability }\end{array}$ & $\begin{array}{c}\text { Screen opening } \\
\text { size }\end{array}$ & Weave \\
\hline Mesh & $\mathrm{mm}$ & $\mathrm{mm}$ & $\mathrm{D}$ & $\mathrm{mm}$ & \\
\hline $40-60$ & $0.420-0.250$ & 0.338 & 45 & 0.200 & Coarse \\
\hline $20-40$ & $0.838-0.420$ & 0.640 & 121 & 0.300 & Medium \\
\hline $10-20$ & $1.980-0.838$ & 1.220 & 500 & 0.600 & Fine \\
\hline
\end{tabular}

In stand-alone (without gravel packing) screen applications, the screen acts as porous barrier to the formation sand. For effective sand control, the screen opening is sized relative to the formation sand.

In this case the rule of the thumb can be applied, which means to size the screen opening to control the $\mathrm{D}_{10}$ - tenth largest accumulative percentile of the formation particles [5].

\section{Case studies - results further to gravel pack operations on Hurezani-Piscu Stejari field}

Hurezani - Piscu Stejari gas field is located in the Getic Depression in the contact area with the Moesian Platform, along the pericarpathian fault.

Based on production tests, hydrocarbon was found in the following formations: Pontian, Meotian and Sarmatian. The production units on this gas field group a number of layers of marl deposits, sand and sandy limestone, poorly consolidated, that give the fault the following physical properties [3]:

$>$ permeability $=0.65 \mathrm{mD}$;

$>$ porosity $=20 \%$;

$>$ fracturing gradient $=0.17 \mathrm{bar} / \mathrm{m}$;

$>$ median sand size $\mathrm{D}_{50}=0.09 \mathrm{~mm}$.

The wells drilled on the field have to be exploited with restricted flow rates $(3.5 \mathrm{~mm}$ or 4 $\mathrm{mm}$ choke) not to drag formation sand.

A series of consolidation operations have been performed to increase production performances of this field that resulted in increasing monthly production from the entire field, as may be seen in figure 5 .

Gravel packing has been performed at production units at an average depth of 1,800 m, using filters of $23 / 8 "$ x 0.008 " gauge assembled in sections of $28 \mathrm{~m}$.

For the gravel pack a gravel sand of 40-60 mesh was used in quantities between 550 $1,600 \mathrm{~kg} /$ well [3]. After performing the gravel pack operation the wells were able to produce through larger chokes $(5 \mathrm{~mm}$ and $6 \mathrm{~mm}$ ) without having sand production. 


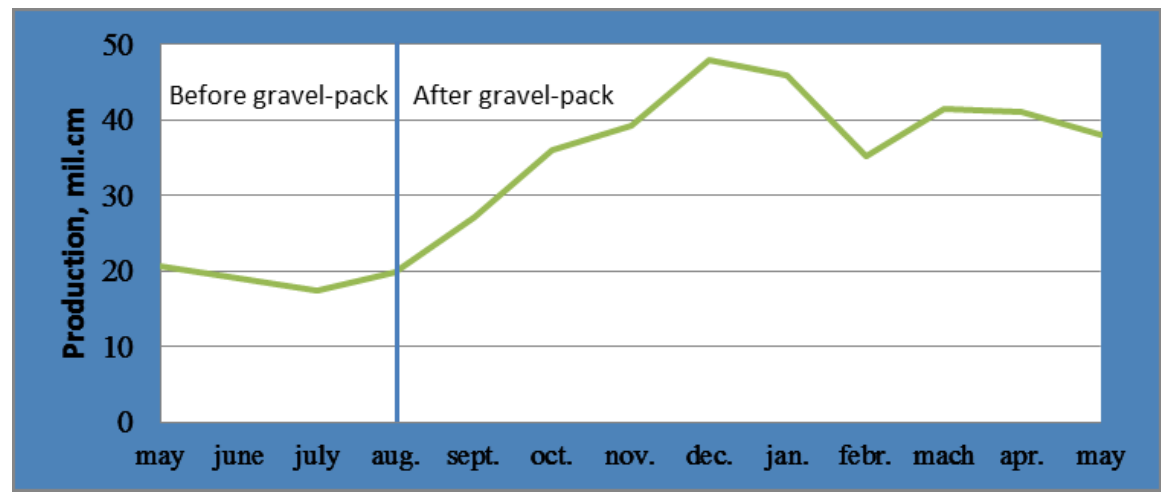

Fig. 5. Impact of gravel-pack operations on monthly production

\section{Conclusions}

Natural gas wells that produce from poorly consolidated formations cannot produce at maximum flow rates but at lower flow rates, not to cause sand floods in the layer. To improve the performance of such wells it is mandatory to use technologies that impede formation sand from entering in the well.

One of the most efficient sand control method is gravel packing. This method can be successfully applied by accurately sizing the gravel sand, sizing the filter according to the formation sand size and by using a procedure able to rigorously comply with the requirements of a gravel packing operation.

Acknowledgment: The authors would like to thank Romgaz for facilitating the access to technical information and documentaries on the subject matter of this article.

\section{References}

1. P. Svoronos, I. Oltean, Proiectarea exploatării zacamintelor de gaze (Editura Tehnica, Bucuresti, 1979)

2. N. Macovei, Deschiderea stratelor productive (Editura Universității Petrol-Gaze, Ploiești, 2008)

3. *** Romgaz Documentation

4. $\quad * * *$ Schlumberger Sand Control Engineering Manual, Volume 1 (Schlumberger, 1992)

5. *** Baker Oil Tools Sand Control Screen Application Guide (Baker Oil Tools, 2008). 